\title{
Clinical course following diabetic ocular palsy
}

\author{
D. LESLIE \\ M.R.C.P.
}

C. ELLIS
M.R.C.P.

Diabetic Department, King's College Hospital, London SE5 9RS

\section{Summary}

Eleven patients who had a diabetic ocular palsy were reviewed. Clinical evidence of microangiopathy or atherosclerosis was infrequent, thus such a palsy does not presage subsequent diabetic complications nor do these observations support the suggestion that diabetic ocular palsies are caused by vascular disease.

\section{Introduction}

External ocular palsies are recognized as occurring in association with diabetes mellitus. While these palsies have been attributed to vascular disease there have been only two studies on the pathology of the affected nerves. Asbury et al. (1970) reported a patient who had microangiopathy in the form of hyaline thickening in the arterioles and capillaries of the affected third nerve. They could not demonstrate any pathology in the opposite third nerve despite a previous palsy on that side and neither they nor Dreyfus, Hakin and Adams (1957) found any significant vascular occlusion. Zorilla and Kosak (1967) reported vascular disease in only fourteen out of twenty-four diabetics with ocular palsies based on electrocardiographic abnormalities and absent peripheral pulses. All of these ocular palsies completely recovered after several months. If they were due to vascular abnormalities one might expect recurrence or evidence of other vascular disease during the years which follow. There are no reports of the clinical course following diabetic ophthalmoplegia. The authors have reviewed eleven diabetics with ocular palsy, and report the clinical features at presentation and their subsequent clinical course.

\section{Patients and methods}

Patients under the care of the Diabetic Department at King's College Hospital were studied. There were thirteen instances of diabetic ophthalmoplegia in those eleven patients who were reviewed. Clinical features are summarized in Table 1.

One patient (no. 4) had three separate episodes of ophthalmoplegia. Case no. 3 alone had ptosis of the affected eye. All the patients had normal pupillary reactions to light and accommodation.

Three patients (nos 3, 9 and 10) were judged to have poor diabetic control, with random blood sugars at the presentation of the palsy and in the preceding year generally greater than $15 \mathrm{mmol} / \mathrm{l}$. Two patients (nos 1 and 8 ) had moderate diabetic control (blood sugars 5-15 mmol/l) and the other six had good diabetic control (blood sugars always less than $10 \mathrm{mmol} / \mathrm{l})$.

On presentation with the palsy, three patients (nos 1, 2 and 3) had absent ankle jerks, one patient

TABLE 1. Details of diabetics with ocular palsies

\begin{tabular}{|c|c|c|c|c|c|c|c|c|}
\hline $\begin{array}{c}\text { Patient } \\
\text { no. }\end{array}$ & Age & Sex & $\begin{array}{l}\text { Nerve } \\
\text { palsy }\end{array}$ & $\begin{array}{l}\text { diabetes } \\
\text { (years) }\end{array}$ & $\begin{array}{c}\text { Duration } \\
\text { palsy } \\
\text { (months) }\end{array}$ & $\begin{array}{l}\text { review } \\
\text { (years) }\end{array}$ & BP & Treatment \\
\hline $\begin{array}{c}1 \\
2 \\
3 \\
4 a \\
4 b \\
4 c \\
5 \\
6 \\
7 \\
8 \\
9 \\
10 \\
11\end{array}$ & $\begin{array}{l}83 \\
66 \\
41 \\
63 \\
69 \\
71 \\
64 \\
75 \\
55 \\
63 \\
39 \\
75 \\
63\end{array}$ & $\begin{array}{l}\mathbf{F} \\
\mathbf{M} \\
\mathbf{M} \\
\mathbf{M} \\
\mathbf{M} \\
\mathbf{M} \\
\mathbf{M} \\
\mathbf{M} \\
\mathbf{M} \\
\mathbf{M} \\
\mathbf{M} \\
\mathbf{F} \\
\mathbf{F}\end{array}$ & $\begin{array}{l}\text { L. } 3 \\
\text { L.3 } \\
\text { L.3 } \\
\text { R. } 3 \\
\text { L.6 } \\
\text { R. } 3 \\
\text { L.3 } \\
\text { L. } 6 \\
\text { R. } 6 \\
\text { R.6 } \\
\text { R. } 6 \\
\text { R. } 6 \\
\text { L. } 6\end{array}$ & $\begin{array}{c}0 \\
4 \\
0 \\
0 \\
6 \\
8 \\
1 \\
0 \\
0 \cdot 3 \\
10 \\
23 \\
10 \\
10\end{array}$ & $\begin{array}{l}6 \\
4 \\
3 \\
2 \\
3 \\
1 \\
5 \\
2 \\
2 \\
2 \\
1 \\
1 \\
9\end{array}$ & $\begin{array}{l}10 \cdot 3 \\
3 \cdot 8 \\
1 \\
8 \cdot 6 \\
\\
\\
2 \cdot 1 \\
0 \cdot 8 \\
5 \cdot 3 \\
6 \cdot 0 \\
3 \cdot 0 \\
0 \cdot 7 \\
8\end{array}$ & $\begin{array}{l}160 / 80 \\
220 / 120 \\
130 / 80 \\
160 / 100 \\
150 / 100 \\
150 / 100 \\
150 / 80 \\
160 / 80 \\
120 / 70 \\
140 / 90 \\
110 / 70 \\
120 / 80 \\
220 / 110\end{array}$ & $\begin{array}{l}\text { O.H. } \\
\text { O.H. } \\
\text { I } \\
\text { O.H. } \\
\text { O.H. } \\
\text { O.H. } \\
\text { D } \\
\text { D } \\
\text { D } \\
\text { I } \\
\text { I } \\
\text { I } \\
\text { I }\end{array}$ \\
\hline \multicolumn{2}{|c|}{$\mathbf{O}=$ Onset } & & Diet & O. & $=$ Oral h & glyca & \multicolumn{2}{|c|}{$I=$ Insulin } \\
\hline
\end{tabular}


(no. 4c) had absent foot pulses and one (no. 3) had persistent proteinuria. Two patients (nos 8 and 9) had only mild background retinopathy, with micro-aneurysms and hard exudates.

The period of follow-up ranged from 9 months to 10 years 4 months, with a mean of 5 years. Two patients (nos 7 and 11) have developed mild background retinopathy with a few microaneurysms. In those two patients who had retinopathy at presentation, only that of no. 9 has progressed to neovascularization. Three patients (nos 2, 5 and 11) are on anti-hypertensive therapy, while the others remain normotensive. Only no. 4 lost his foot pulses and no. 3 remains the sole patient with proteinuria. No further patients lost their reflexes.

\section{Discussion}

Microangiopathy and arteriosclerosis were infrequent in this series of diabetics with ocular palsies, either at the time of onset or up to 10 years following recovery. Only one patient had a recurrence of his palsy. These findings do not support the suggestion that such ocular palsies are caused by vascular disease. The present observations confirm the frequency of third and sixth nerve involvement
(Zorilla and Kosak, 1967) and the normal pupillary function in the third nerve palsy (Goldstein and Cogan, 1960). Most of the palsies had recovered by 3 months. The age range of patients and the duration of the palsies concur with previous findings (Zorilla and Kosak, 1967; Weinstein and Dolger, 1948). It is apparent that an ocular palsy may occur in the presence of good diabetic control, irrespective of the nature of treatment and may be either the presenting feature or a later complication of the disease.

\section{References}

Asbury, A.K., Aldredge, H., Herschberg, R. \& Fisher, C.M. (1970) Ocular motor palsy in diabetes mellitus: a clinico-pathological study. Brain, 93, 555.

Dreyfus, P.M., HaKim, S. \& AdAMS, R.D. (1957) Diabetic ophthalmoplegia. Archives of Neurology and Psychiatry. Chicago, 77, 337.

Goldstein, J.E. \& Cogan, G. (1960) Diabetic ophthalmoplegia with special reference to the pupil. Archives of Ophthalmology. Chicago, 64, 592.

Weinstein, E.A. \& Dolger, H. (1948) External ocular muscle palsies occurring in diabetes. Archives of Neurology and Psychiatry. Chicago, 60, 597.

Zorilla, E. \& KosAK, G.P. (1967) Ophthalmoplegia in diabetes mellitus. Annals of Internal Medicine, 67, 968. 